Article

\title{
Removal of Metaldehyde from Water Using a Novel Coupled Adsorption and Electrochemical Destruction Technique
}

\author{
Mohammed A. Nabeerasool ${ }^{1}$, Andrew K. Campen ${ }^{2}$, David A. Polya ${ }^{1}$, Nigel W. Brown ${ }^{2}$ \\ and Bart E. van Dongen ${ }^{1, *}$
}

1 School of Earth Atmospheric and Environmental Sciences and Williamson Research Centre for Molecular Environmental Science, University of Manchester, Manchester M13 9PL, UK;

E-Mails: akmez.nabeerasool@manchester.ac.uk (M.A.N.); david.polya@manchester.ac.uk (D.A.P.)

2 Arvia Technology Ltd., The Innovation Centre, Sci-Tech Daresbury, Keckwick Lane,

Cheshire WA4 4FS, UK; E-Mails:andrew.campen@arviatechnology.com (A.K.C.);

nigel.brown@arviatechnology.com (N.W.B.)

* Author to whom correspondence should be addressed;

E-Mail: bart.vandongen@manchester.ac.uk; Tel.:+44-161-306-7460.

Academic Editor: Say-Leong Ong

Received: 17 March 2015 / Accepted: 15 June 2015 / Published: 19 June 2015

\begin{abstract}
Metaldehyde is a selective pesticide applied to control snails and slugs and which, particularly when application rates are high and during periods of high rainfall, may find its way into water courses, some of which may be used as drinking water supplies. Existing water treatment processes have been inadequate for reducing metaldehyde residual levels (up to $8 \mu \mathrm{g} / \mathrm{L}$ ) found in some waters to below the EU/UK statutory limit of $0.1 \mu \mathrm{g} / \mathrm{L}$. Here a novel coupled adsorption and electrochemical regeneration technology is tested to determine if it is capable of effectively removing metaldehyde. We demonstrate that metaldehyde is not only adsorbed on the adsorbent used but is also destroyed during the regeneration stage, resulting in residual metaldehyde concentrations below the EU/UK regulatory limit for drinking water. No known harmful breakdown by-products were observed to be generated by the process. The effectiveness of the process seems unaffected by organic-rich peat water, indicating the potential for the treatment of drinking water much of which in the UK is derived from upland peaty catchments. Furthermore, successive spiking experiments showed that this technology has the potential to be applied as a continuous process without the generation of substantial waste products.
\end{abstract}


Keywords: adsorption; electrochemical regeneration; metaldehyde; pesticide

\section{Introduction}

Access to clean drinking water is a basic human need but as many as 750 million people in the world do not have access to it [1]. Freshwater sources are often contaminated by industrial waste, pesticides, fertilizers, and other pollutants such as microorganisms, heavy metals and other hazardous chemicals which make water unfit for human consumption and which can be a key factor in water-related diseases [2]. The pesticide, metaldehyde, is one such drinking water pollutant for which there are not only concerns about its health impacts [3] but for which there are considerable practical difficulties in its efficient removal [4].

Metaldehyde, the more widely used name for 2,4,6,8-tetramethyl-1,3,5,7-tetraoxacyclooctane, is a molluscicide extensively used worldwide, particularly in wet regions [5]. In the United Kingdom (UK) alone between 2008 and 2012, over 1400 tonnes of metaldehyde have been used [6]. Metaldehyde is long-lived in the environment, soluble in water with a solubility of $200 \mathrm{mg} / \mathrm{L}$ at $20{ }^{\circ} \mathrm{C}$, and hence highly mobile in aqueous environments [7]. However, leaching of metaldehyde in water sources during wet seasons in particular can pose a serious threat to water quality since, so far, existing technologies, such as adsorption on activated carbon, and advanced oxidation processes have shown to be ineffective in comprehensively reducing the amount of metaldehyde to European and UK regulatory limits of $0.1 \mu \mathrm{g} / \mathrm{L}$ in water [8-10]. In 2011, most regions in the UK failed to comply with this limit [10,11].

The efficient removal of any pesticide from water is dependent on their chemical and physical characteristics. Metaldehyde is a cyclic tetramer of acetaldehyde and this makes chlorination or ozonation treatment methods ineffective [12]. Hall et al. [13] further suggested that the low $\mathrm{K}_{\text {ow }}$ of 0.12 for metaldehyde is the reason why many current treatment processes are unable to adequately remove metaldehyde. Photocatalysis using nano-sized zinc oxide composites [14] and advanced oxidation processes using $\mathrm{UV} / \mathrm{TiO}_{2}$ and $\mathrm{UV} / \mathrm{H}_{2} \mathrm{O}_{2}$ [15,16] are promising for removal of micro-pollutants but they are costly and have yet to show that they can meet the regulatory limit set for metaldehyde. Recently, Busquets et al. [7] reported that metaldehyde can successfully be removed down to regulatory limits using an adsorption process based on phenolic carbon. However, this process is not chemical free and there is concern over the possibility of phenolic components from the adsorbent leaching out into water. An adsorption process developed by Veolia Water Solutions \& Technologies (Pairs, France) and Affinity Water [17] can also reduce metaldehyde to below regulatory levels. However, this process makes use of Powdered Activated Carbon (PAC), which is costly, and the process is solely based on adsorption thus leading to the requirement of disposing of a substantial amount of PAC waste.

Recently, one of us (Nigel Brown) has been involved in the development of a new, coupled adsorption and electrochemical destruction technology, the Arvia ${ }^{\mathrm{TM}}$ (Cheshire, UK) Process, for the removal of organic contaminants from waters $[18,19]$. The process uses a low capacity graphitic material (a graphite intercalation compound; Nyex ${ }^{\mathrm{TM}}$ (Cheshire, UK), a material comprising both graphitic edges and basal planes which are believed to provide a range of adsorption sites) as an 
effective adsorbent that can be rapidly and cost-effectively regenerated electrochemically [20-22]. Although a relatively low sorption capacity material, the lack of intra-granular porosity provides for both rapid sorption and regeneration kinetics, whilst the relatively high electrical conductivity means that electrochemical regeneration could potentially be carried out using relatively little energy [23]. The treatment process proceeds via a batch process comprising treatment cycles with three main stages, (i) adsorption; (ii) sedimentation; and (iii) electrochemical regeneration, with the efficiency of adsorption of the contaminant on the $\mathrm{Nyex}^{\mathrm{TM}}$ in the case of low/trace concentrations and the amount of voltage applied to the system during the electrochemical regeneration step at higher concentrations being the limiting steps, respectively. The process has shown to be effective in removing some organic pollutants, such as Acid Violet 17, from wastewaters [18,19]. However, it remains unclear if this adsorption and electrochemical regeneration process can be used to remove metaldehyde from drinking waters to below drinking water standards.

Thus the aims of this study were (i) to determine if metaldehyde in drinking waters can be effectively removed/destroyed using this novel coupled adsorption and electrochemical destruction technology; (ii) to identify the optimum conditions for its removal; (iii) to determine if any significant concentrations of harmful breakdown products are formed; and (iv) since upland peat areas are an important source of drinking water in many parts of the EU and the UK, to assess the efficiency of metaldehyde removal for such relatively high natural organic matter (NOM) waters.

\section{Materials/Reagents and Sample Preparation}

Analytical grade metaldehyde (98\% purity) was purchased from Lonza Chemical; D5-atrazine (99\% purity), ethyl acetate, methanol, formic acid and sodium thiosulfate pentahydrate were all purchased from Sigma-Aldrich (Irvine, UK). Nyex ${ }^{\mathrm{TM}}$ 1102, provided by Arvia ${ }^{\mathrm{TM}}$ Technology Limited, was similar to previously characterized batches of $\mathrm{Nyex}^{\mathrm{TM}} 100$ and $\mathrm{Nyex}^{\mathrm{TM}} 1000$, contained above $90 \%$ carbon and had a particle size range of 100 to $700 \mu \mathrm{m}$ [18-23]. The $\mathrm{Nyex}^{\mathrm{TM}}$ was washed with tap water several times prior to use. ENVI-18 cartridges for extracting the samples were purchased from Kinesis (Bothell, WA, USA). The sodium thiosulfate solution was prepared by dissolving $0.9 \mathrm{~g}$ of sodium thiosulfate crystals in $50 \mathrm{~mL}$ deionised water [24]. Metaldehyde stock solutions $(\sim 15,000 \mu \mathrm{g} / \mathrm{L})$ were prepared by mixing metaldehyde in deionised water for $72 \mathrm{~h}$. A range of metaldehyde test solutions (from 12,000 to $10 \mu \mathrm{g} / \mathrm{L}$ ) were prepared by diluting these stock solutions with $18 \mathrm{M} \Omega \cdot \mathrm{cm}^{-1}$ deionised water. Experiments without a regeneration stage were also performed to evaluate the adsorptive capacity of the system alone. High NOM peat water samples were obtained on 17 October 2013 from the Crowden Great Brook stream (Peak District; about $25 \mathrm{~km}$ east of Manchester, UK). Peat water test solutions were prepared by mixing $500 \mathrm{~mL}$ of the peat water and $500 \mathrm{~mL}$ of the metaldehyde stock solution.

\subsection{Adsorption and Organic Destruction Experiments}

Adsorption isotherm experiments were conducted by mixing (magnetic stirrer; $700 \mathrm{rpm}$; for $60 \mathrm{~min}$ ) the Nyex ${ }^{\mathrm{TM}} 1102$ adsorbent $(10 \mathrm{~g})$ with metaldehyde solutions $(100 \mathrm{~mL}$; concentrations between 12,000 and $100 \mu \mathrm{g} / \mathrm{L}$ ) in a temperature controlled laboratory at $20 \pm 2{ }^{\circ} \mathrm{C}$. The mixing time of $60 \mathrm{~min}$ had previously been determined from a kinetic study (Figure 1A) to be a sufficient time to reach 
equilibrium. Aliquots $(10 \mathrm{~mL})$ were collected every $10 \mathrm{~min}$, filtered $(0.45 \mu \mathrm{m}$ nylon syringe filter $)$ and analysed by liquid chromatography mass spectrometry (LCMS) after the addition of $10 \mu \mathrm{L}$ of the sodium thiosulfate solution to ensure that any chlorine was removed from the samples. This is necessary, as, during the regeneration phase, chlorine may be formed due to the use of the acidified sodium chloride solution as a catholyte.

The amount of metaldehyde, $q_{e}(\mu \mathrm{g} / \mathrm{g})$, adsorbed on the adsorbent was determined using Equation (1):

$$
q_{e}=\left(C_{0}-C_{e}\right) V / m
$$

where $C_{0}$ is the initial concentration of metaldehyde in solution $(\mu \mathrm{g} / \mathrm{L}), C_{e}$ is the concentration of metaldehyde remaining in solution $(\mu \mathrm{g} / \mathrm{L}), m$ is the mass of adsorbent used $(\mathrm{g})$, and $V$ is the volume of metaldehyde solution (L) for the whole experiment. Corrections were not made for any changes in adsorbent/solution ratios after taking sacrificial samples, because thorough mixing ensured that these ratios were conserved during sampling.

The observed metaldehyde/Nyex ${ }^{\mathrm{TM}}$ adsorption data were tested against a Freundlich isotherm model given by Equations (2) and (3):

$$
q_{e}=K_{f} C_{e}^{1 / n}
$$

and

$$
\log q_{e}=(1 / n) \log C_{e}+\log K_{f}
$$

and for which the Freundlich model parameters, $\mathrm{n}$ and $K_{f}$, may accordingly be derived from a best fit regression line on a $\log \left(\mathrm{q}_{\mathrm{e}}\right)$ vs. $\log \left(\mathrm{C}_{\mathrm{e}}\right)$ plot.

The data were also fitted to a Langmuir adsorption isotherm model given by Equations (4) and (5).

$$
\begin{gathered}
q_{e}=\frac{Q^{o} K C_{e}}{1+K C_{e}} \\
\frac{1}{q_{e}}=\frac{1}{Q^{0}}+\frac{1}{K Q^{0}} * \frac{1}{C_{e}}
\end{gathered}
$$

where $\frac{1}{K Q^{0}}$ and $\frac{1}{Q^{0}}$ are the model constants (with $K Q^{0}$ equivalent to the Langmuir constant, $\alpha$ ) and are derivable from a best fit regression line to a plot of $1 / \mathrm{q}_{\mathrm{e}} v s .1 / \mathrm{C}_{\mathrm{e}}$.

Metaldehyde removal/destruction experiments were conducted using the same laboratory scale sequential batch equipment as described by Asghar et al. [18] in a temperature controlled laboratory at $20 \pm 2{ }^{\circ} \mathrm{C}$. Details of the experimental set up, including schematics, can be found in Asghar et al. [18] and Mohammed et al. [19]. For the optimization experiments, the cell was loaded with $200 \mathrm{~g}$ of pre-cleaned wet Nyex ${ }^{\mathrm{TM}}$ (approximately $100 \mathrm{~g}$ dry weight) and $1 \mathrm{~L}$ of metaldehyde test solution with known concentration was added, and the experiment was conducted for 5 treatment cycles. Under standard conditions, a treatment cycle consists of: (i) a mixing phase (15 min), during which the Nyex $^{\mathrm{TM}}$ and the test solution were well mixed by blowing air through it; (ii) a settling phase (10 min); and (iii) regeneration phase (15 min) during which a current of $0.5 \mathrm{~A}\left(10 \mathrm{~mA} / \mathrm{cm}^{2}\right)$ was passed through the adsorbent bed to destroy the adsorbed metaldehyde. After each cycle, three $10 \mathrm{~mL}$ aliquots were collected, filtered (Whatman 541) and analysed in triplicate by liquid chromatography mass spectrometry (LCMS) after the addition of $10 \mu \mathrm{L}$ of the sodium thiosulfate solution. The peat water experiments were performed using the same procedure. 
In case of the low concentration experiments a similar set up was used but with $1.5 \mathrm{~L}$ of metaldehyde test solution (approximately $10 \mu \mathrm{g} / \mathrm{L}$ ) and the experiments was conducted for 7 treatment cycles. Aliquots $(200 \mathrm{~mL})$ were collected after Cycle 2 and 4 and a $900 \mathrm{~mL}$ aliquot was obtained after the last treatment cycle. All the aliquots were filtered (Whatman 541), and concentrated using the solid phase extraction (SPE) method developed by Kinesis [25]. In short, SPE columns (TELOS ${ }^{\mathrm{TM}}$ ENV $200 \mathrm{mg} / 6 \mathrm{~mL}$ ) were conditioned with ethyl acetate ( 2 column volumes), methanol (2 column volumes) and deionised water ( 1 column volume) while making sure the pre-conditioned columns did not dry out. Metaldehyde was extracted by passing the aliquot through the column at a flow rate of approximately 30 to $35 \mathrm{~mL} / \mathrm{min}$ before drying the SPE column under vacuum until the sorbent became a uniform light brown colour. The dried columns were soaked in $2 \mathrm{~mL}$ of ethyl acetate for $5 \mathrm{~min}$, the elute was collected and a further $2 \mathrm{~mL}$ ethyl acetate was added and allowed to elute. The combined samples were blown down from 100 to $25 \mu \mathrm{L}$ and analysed using gas chromatography mass spectrometry (GCMS). The detection limit reached using this protocol was $0.01 \mu \mathrm{g} / \mathrm{L}$. To ensure repeatability and determine recovery rates, control metaldehyde solutions were subjected to the same extraction procedure and analysed by gas chromatography mass spectrometry (GCMS).

\subsection{Liquid Chromatography Mass Spectrometry (LCMS) and Chromatography Mass Spectrometry (GCMS) Analysis}

LCMS analyses was performed using an Agilent 1200 HPLC instrument coupled to an Agilent 6130 quadrupole mass spectrometer equipped with a multimode source operated in atmospheric-pressure chemical ionization (APCI) positive ion mode based on a protocol adapted from the Environment Agency for determination of metaldehyde in water [24]. Metaldehyde was analysed using a normal phase LCMS Kinetex C18 HPLC column ( $3 \mu \mathrm{m},>150 \mathrm{~mm} \times 2.1 \mathrm{~mm}$ internal diameter; Phenomenex) and a guard column of the same material. LCMS settings were as follows: nebulizer pressure 20 psig, vaporiser temperature $250{ }^{\circ} \mathrm{C}$, drying gas (N2) flow $6 \mathrm{~L} / \mathrm{min}$ and temperature $200{ }^{\circ} \mathrm{C}$, capillary voltage $2 \mathrm{kV}$ and corona current $5 \mu \mathrm{A}$. In order to increase sensitivity/reproducibility, ion scanning was performed in single ion monitoring (SIM) mode using acetaldehyde $[\mathrm{M}+\mathrm{Na}]+$ and metaldehyde $[\mathrm{M}+\mathrm{Na}]+$ ions, ion peaks at $\mathrm{m} / \mathrm{z} 67$ and 199, respectively. Separation was achieved at $30{ }^{\circ} \mathrm{C}$ with a flow rate of $0.4 \mathrm{~mL} \cdot \mathrm{min}^{-1}$ and using the following gradient profile: $60 \% \mathrm{~A}$ and $40 \% \mathrm{~B}(0 \mathrm{~min}), 60 \% \mathrm{~A}$ and $40 \% \mathrm{~B}(1 \mathrm{~min}), 40 \% \mathrm{~A}$ and $60 \% \mathrm{~B}(6 \mathrm{~min}), 40 \% \mathrm{~A}$ and $60 \% \mathrm{~B}(9.5 \mathrm{~min}), 40 \% \mathrm{~A}$ and $60 \% \mathrm{~B}$ (12 min); where $\mathrm{A}=$ Water containing $0.25 \%$ formic acid and $\mathrm{B}=$ Methanol containing $0.25 \%$ formic acid; all HPLC grade. The sample injection rate was $10 \mu \mathrm{L}$ and the retention time of metaldehyde was 6.9 min.

GCMS was performed using an Agilent 789A GC interfaced to an Agilent 5975C MSD mass spectrometer operating with electron ionisation at $40 \mathrm{eV}$ and scanning from $\mathrm{m} / \mathrm{z} 50$ to 600 at 2.7 scans/s based on a protocol adapted from the Environment Agency for determination of metaldehyde in water [24]. The GC was equipped with an Agilent 7683B auto sampler and a programmable temperature variation (PTV) inlet. The samples were injected in pulsed spit-less injection mode ( $1 \mu \mathrm{L}$; inlet pressure of 25 psi for $0.25 \mathrm{~min}$ ) and separated on an HP-5 capillary column (J\&W scientific column 5\% diphenyldimethyl polysiloxane; length $30 \mathrm{~m}$, I.D. $250 \mu \mathrm{m}$, film thickness $0.25 \mu \mathrm{m})$. The samples were run at a constant flow $(1 \mathrm{~mL} / \mathrm{min})$ with $\mathrm{He}$ as a carrier gas. The heated 
interface temperature was set to $280{ }^{\circ} \mathrm{C}$, with the mass source temperature at $230{ }^{\circ} \mathrm{C}$ and the MS quadrupole at a temperature of $150{ }^{\circ} \mathrm{C}$. The samples were injected at $35{ }^{\circ} \mathrm{C}$ and the oven was programmed to $260{ }^{\circ} \mathrm{C}$ at $20{ }^{\circ} \mathrm{C} / \mathrm{min}$ at which it was held isothermally for $0.5 \mathrm{~min}$. Peaks were acquired both in scan and SIM mode at ion peaks of $m / z=45$ and 89.

\section{Results and Discussion}

\subsection{Adsorption Experiments}

Initial adsorption experiments using metaldehyde concentrations ranging from 250 to $12,000 \mu \mathrm{g} / \mathrm{L}$ were undertaken to determine the maximum metaldehyde uptake by the $\mathrm{Nyex}^{\mathrm{TM}}$ and the minimum contact time required to achieve equilibrium.

For both the $2000 \mu \mathrm{g} / \mathrm{L}$ and $12,000 \mu \mathrm{g} / \mathrm{L}$ metaldehyde solutions, equilibrium was reached within $20 \mathrm{~min}$ (Figure 1A).
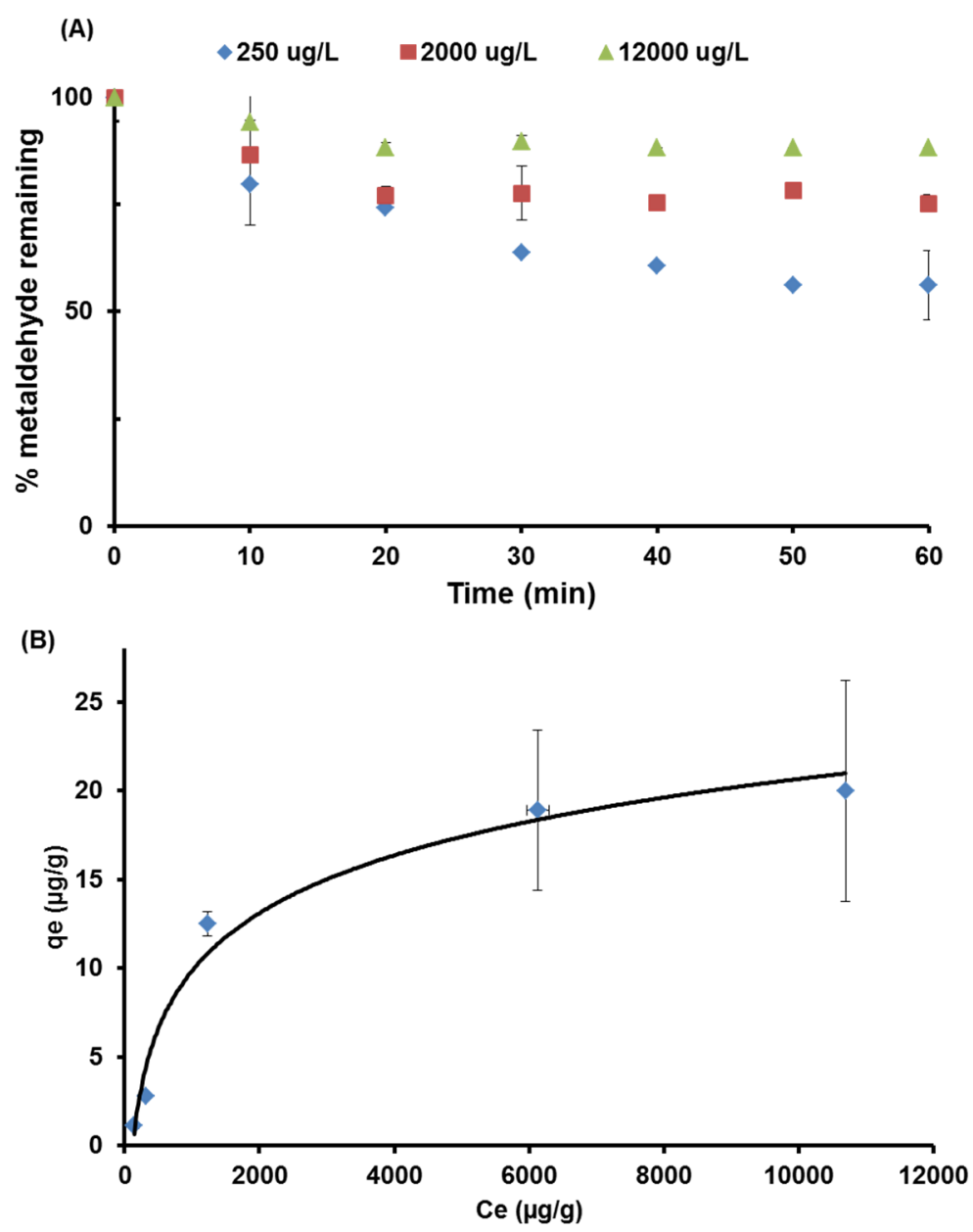

Figure 1. (A) Kinetics of metaldehyde adsorption onto $\mathrm{Nyex}^{\mathrm{TM}}$ 1102. Metaldehyde remaining expressed as a percentage of the initial metaldehyde concentrations of 250, 2000 or $12,000 \mu \mathrm{g} / \mathrm{L}$ as indicated; (B) Adsorption isotherm of metaldehyde on $\mathrm{Nyex}^{\mathrm{TM}} 1102$. Equilibration time $60 \mathrm{~min}$; initial $\mathrm{pH}$ 6-7. Bars indicate the error; when they are not visible the error bar is smaller than the symbol used. 
In the case of the lowest initial concentration, $250 \mu \mathrm{g} / \mathrm{L}$, equilibrium was not reached until $50 \mathrm{~min}$. However, a relatively larger proportion of metaldehyde in the starting solution was removed in the case of the lowest concentration (45\%) compared to $25 \%$ for the $2000 \mu \mathrm{g} / \mathrm{L}$ and $12 \%$ for the $12,000 \mu \mathrm{g} / \mathrm{L}$ solutions. The maximum amount of metaldehyde that could be adsorbed on the Nyex ${ }^{\mathrm{TM}}$ based on the adsorption isotherm (Figure 1B) was found to be approximately $18 \mu \mathrm{g}$ metaldehyde/g Nyex $^{\mathrm{TM}}$. This clearly shows that, despite $\mathrm{Nyex}^{\mathrm{TM}}$ being a largely non-porous material, metaldehyde can nevertheless be adsorbed on $\mathrm{Nyex}^{\mathrm{TM}}$ and thus could potentially be removed using the combined adsorption and electrochemical regeneration process. However, the adsorption capacity is not as high as for some other adsorbent materials. Busquet et al. [7] for instance showed that the adsorption capacity of phenolic carbon is about $76 \mathrm{mg}$ metaldehyde/g adsorbent, much higher than that observed here.

The adsorption data fits poorly to a Freundlich isotherm model (Figure 2A) - an apparently first order linear trend of $\log \left(\mathrm{q}_{\mathrm{e}}\right)$ against $\log \left(\mathrm{C}_{\mathrm{e}}\right)$ at low metaldehyde concentrations then deviates substantially from this with a plateauing of $\log \left(\mathrm{q}_{\mathrm{e}}\right)$ values once initial metaldehyde concentrations are sufficiently high to approach the saturation limit $(1.26=\log (\sim 18 \mu \mathrm{g} / \mathrm{g}))$ of the Nyex ${ }^{\mathrm{TM}}$.
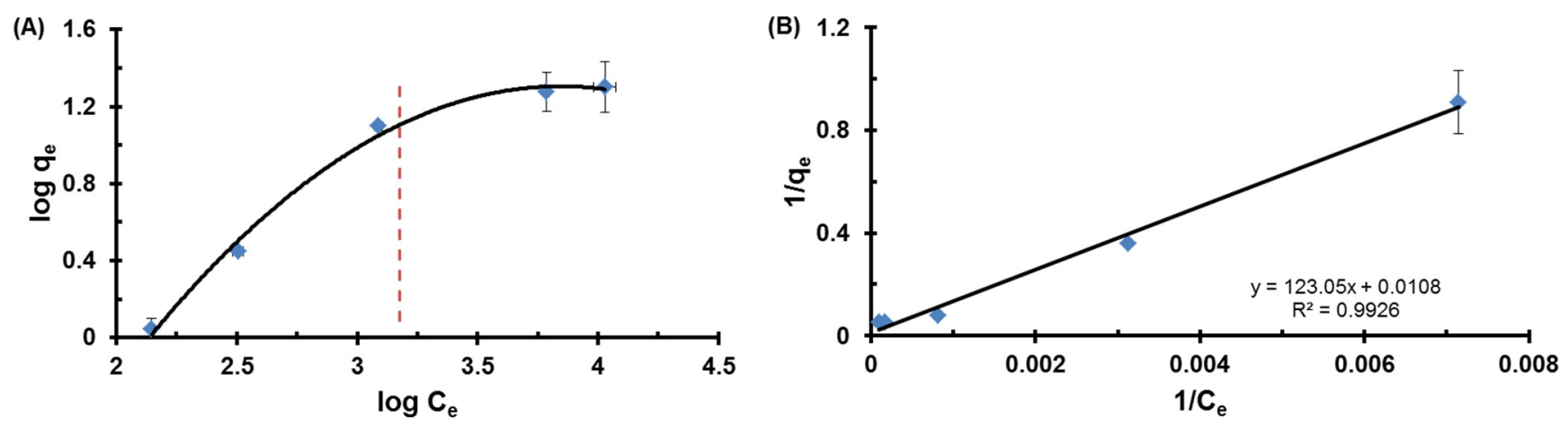

Figure 2. (A) Freundlich log-log plot of solid-phase concentration ( $\mathrm{q}_{\mathrm{e}}$ ) versus liquid-phase concentration $\left(\mathrm{C}_{\mathrm{e}}\right)$ at equilibrium. Dashed vertical line represent mean metaldehyde removed per treatment cycle as determined from Figure 3A; (B) Langmuir plot for the metaldehyde/Nyex ${ }^{\mathrm{TM}} 1102$ system, where $\mathrm{q}_{\mathrm{e}}$ and $\mathrm{C}_{\mathrm{e}}$ are in $\mu \mathrm{g} / \mathrm{g}$ and $\mu \mathrm{g} / \mathrm{L}$, respectively. Bars indicate the error, when they are not visible the error bar is smaller than the symbol used.

In contrast, the adsorption data fit very well to the Langmuir model (Figure 2B) with an excellent linear correlation $\left(R^{2}=0.99\right)$ a Langmuir constant, $\alpha$, of $0.08 \mu \mathrm{g} / \mathrm{g}$ and $1 / Q^{0}$ of $0.011 \mathrm{~g} / \mu \mathrm{g}$. This strong linear correlation is consistent with a monolayer coverage of the adsorbent material, indicating that the adsorption of metaldehyde is limited by the number of adsorption sites on the Nyex ${ }^{\mathrm{TM}}$ and explaining the relative low adsorption capacity compared to other adsorbent materials.

\subsection{Optimisation of Parameters for Metaldehyde Removal}

To determine if metaldehyde can also be removed/destroyed during the electrochemical destruction/regeneration process, additional experiments were performed at a relatively high starting concentration of $8000 \mu \mathrm{g} / \mathrm{L}$ metaldehyde. The high concentration used was to ensure that the Nyex ${ }^{\mathrm{TM}}$ was (completely) saturated. These experiments showed that $>90 \%$ of $8000 \mu \mathrm{g} / \mathrm{L}$ metaldehyde in water can be removed within five treatment cycles (Figure $3 \mathrm{~A}$ ). 


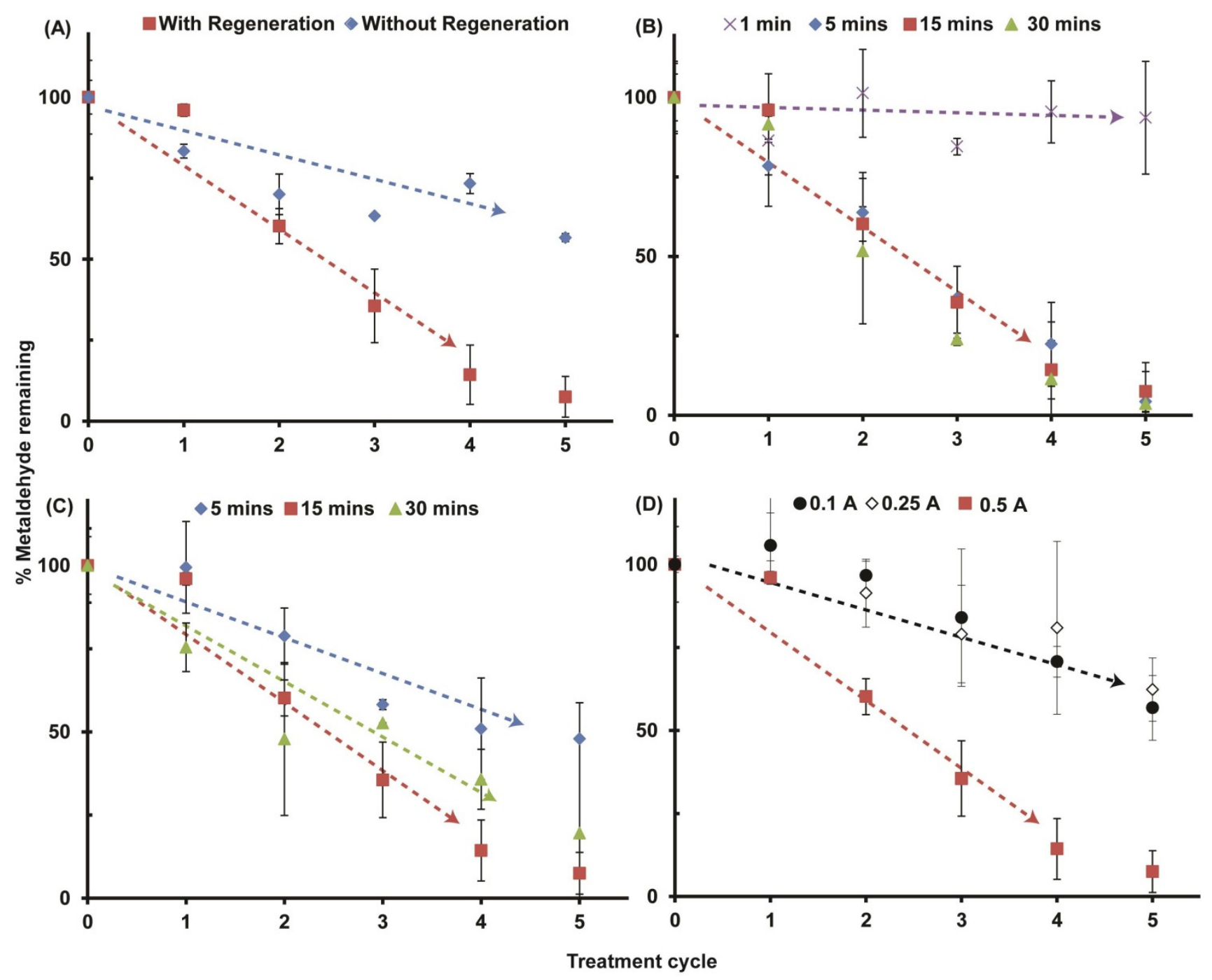

Figure 3. Metaldehyde remaining (expressed as a percentage of initial concentration $\sim 8000 \mu \mathrm{g} / \mathrm{L}$ ) after successive treatment cycles (A) with and without regeneration (15 min; current $0.5 \mathrm{~A}$ ) and mixing (15 min); under (B) varying mixing times at constant regeneration times of $15 \mathrm{~min}$ and current of $0.5 \mathrm{~A} ;(\mathbf{C})$ varying regeneration times at constant mixing time of $15 \mathrm{~min}$ and current of $0.5 \mathrm{~A}$; and (D) varying current at constant mixing time $(15 \mathrm{~min})$ and regeneration time (15 min; current $0.1 \mathrm{~A}, 0.25 \mathrm{~A}$ and $0.5 \mathrm{~A})$. Dotted arrows indicate generalized trends, when there are multiple comparable trends only a single arrow is given. Bars indicate the error, when they are not visible the error bar is smaller than the symbol used.

A broadly linear relation was observed between percentage of metaldehyde removed and the number of treatment cycles for the first four treatment cycles, indicating that on average about $1500 \mu \mathrm{g} / \mathrm{L}$ metaldehyde was removed per treatment cycle. This limiting value for metaldehyde removal is equivalent to $\sim 15 \mu \mathrm{g}$ metaldehyde/g Nyex ${ }^{\mathrm{TM}}$, broadly consistent with the previously determined $18 \mu \mathrm{g}$ metaldehyde/g Nyex ${ }^{\mathrm{TM}}$ adsorption capacity (Figure 1B). After the fourth treatment cycle, the relationship is no longer linear and would suggest that as the concentration of metaldehyde decreases so does the removal rate. A control experiment using the same set up but without the regeneration stage indicated a much lower metaldehyde removal after five treatment cycles (45\%; 
Figure 3A). This study demonstrated that the adsorbent material is effectively regenerated. Previous work on adsorption and electrochemical regeneration of organic loaded on the $\mathrm{Nyex}^{\mathrm{TM}}$ would suggest that metaldehyde is destroyed by conversion to carbon dioxide via a reaction represented by Equation (6) [25] and this is supported by the absence of the breakdown product acetaldehyde (Section 3.3).

$$
\mathrm{C}_{8} \mathrm{H}_{16} \mathrm{O}_{4}+12 \mathrm{H}_{2} \mathrm{O} \rightarrow 8 \mathrm{CO}_{2}+40 \mathrm{H}^{+}+40 e^{-}
$$

This frees the active sites on the Nyex ${ }^{\mathrm{TM}}$ surface for further metaldehyde adsorption during the next cycle.

To determine the optimal experimental conditions, a series of tests were performed on the mixing and regeneration times as well as the current used during the adsorption and electrochemical regeneration process. Varying the mixing time indicated no significant differences in metaldehyde removal if a mixing time of $\geq 5 \mathrm{~min}$ is used (Figure 3B). However, lowering the mixing time to $1 \mathrm{~min}$ resulted in a significant reduction in the removal rate with less than $10 \%$ metaldehyde being removed after five cycles. This indicates that a mixing time of $1 \mathrm{~min}$ is not enough for effective adsorption of metaldehyde on Nyex ${ }^{\mathrm{TM}}$ and also confirms that adsorption is a prerequisite for effective oxidation of metaldehyde, that is, there is no indirect electrochemical oxidation in the bulk phase.

Altering the regeneration time to 5 min caused a significant drop in metaldehyde removal to $52 \%$. Increasing the regeneration time to $30 \mathrm{~min}$ caused only a slight drop in metaldehyde removal indicating that maximal removal can be achieved using a regeneration time of 15 min (Figure 3C). Reduction in performance when the regeneration time was increased from 15 to 30 min could be due to over treatment of the Nyex ${ }^{\mathrm{TM}}$. Mehta and Flora [26] found that electrochemically regenerating activated carbon for extended periods adversely affected the adsorptive capacity and postulated that to be due to a decrease in surface carbonyl groups or to changes in surface area. Lowering the current used caused a significant drop in metaldehyde removal rate resulting in about $60 \%$ of metaldehyde being removed in five cycles at $0.1 \mathrm{~A}$ and $0.25 \mathrm{~A}$, respectively, compared to more than $90 \%$ at $0.5 \mathrm{~A}$ (Figure 3D). This result suggests that at a current of $0.1 \mathrm{~A}$, the voltage generated is insufficient to drive the oxidation reaction (Table 1) with a minimum voltage required for effective regeneration of the adsorbent, this value being in excess of $3.0 \mathrm{~V}$.

Table 1. Typical voltages observed at fixed applied current for regeneration and $\%$ metaldehyde remaining after five cycles, respectively.

\begin{tabular}{ccc}
\hline Current/A & Voltage/V & Metaldehyde Remaining \\
\hline 0.50 & 3.8 & $8 \%$ \\
0.25 & 2.9 & $63 \%$ \\
0.10 & 2.4 & $57 \%$ \\
0.00 & 0.0 & $56 \%$ \\
\hline
\end{tabular}

Combined these experiments showed that (i) metaldehyde is actively being destroyed and the drop in metaldehyde concentration observed is not just caused by adsorption on the Nyex ${ }^{\mathrm{TM}}$ and (ii) maximum metaldehyde removal rates are achieved using a current of $0.5 \mathrm{~A}$, a regeneration time of $15 \mathrm{~min}$ and a minimum mixing time of $5 \mathrm{~min}$. 


\subsection{Evaluation of the Coupled Adsorption and Electrochemical Regeneration Technology for}

\section{Metaldehyde Removal at Low Concentrations}

To determine if this coupled adsorption and electrochemical regeneration process could be used to reduce metaldehyde in water supply systems to below EU and UK standards, additional low concentration experiments were performed. The starting metaldehyde concentration of $11 \mu \mathrm{g} / \mathrm{L}$ was chosen to be comparable in magnitude to the highest concentrations of metaldehyde observed in the UK post-treatment water supply systems, viz. $\sim 8 \mathrm{~g} / \mathrm{L}$ [24]. These experiments show that metaldehyde (from a starting concentration of $11 \mu \mathrm{g} / \mathrm{L}$ ) was clearly removed to residual concentrations well below EU/UK regulatory limits of $0.1 \mu \mathrm{g} / \mathrm{L}$ (Figure 4).

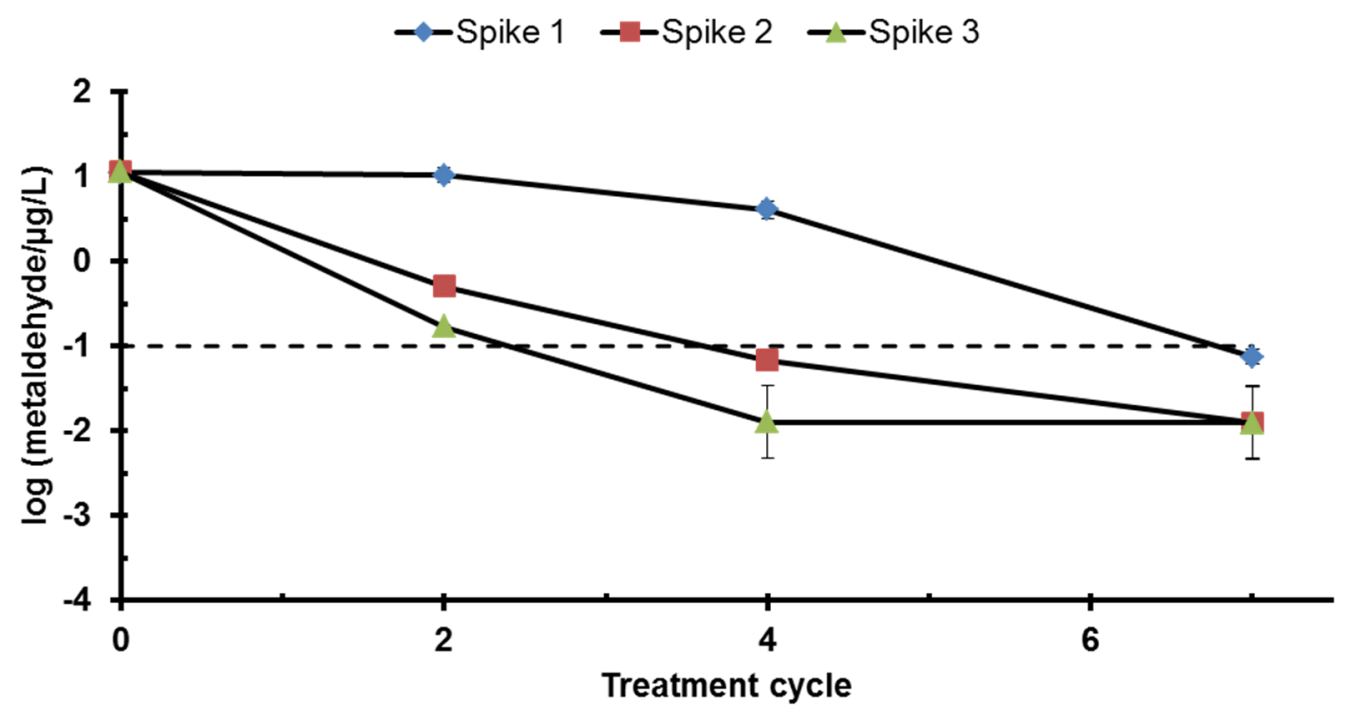

Figure 4. Metaldehyde remaining of triplicate spikes (initial concentration $11 \mu \mathrm{g} / \mathrm{L}$ ) after successive treatment cycles. Mixing times, $15 \mathrm{~min}$; regeneration times, $15 \mathrm{~min}$; current, 0.5 A. Bars indicate the error, when they are not visible the error bar is smaller than the symbol used. Metaldehyde concentrations in all the spikes were reduced to below the EU and UK regulatory limit of $0.1 \mu \mathrm{g} / \mathrm{L}$ [10] (dashed line) after seven treatment cycles.

Additional spiking experiments, using the same adsorbent material but with a fresh batch of metaldehyde solution, showed that the process is repeatable over time and that there was no overloading of the adsorbent material at these comparatively low concentrations. In the later cycles the final concentrations were actually below the detection limit of the equipment used, i.e., below $0.01 \mu \mathrm{g} / \mathrm{L}$. Closer analysis of the results revealed that the process was more effective with increasing number of treatment cycles. The EU/UK regulatory limit of $0.1 \mu \mathrm{g} / \mathrm{L}$ was met within four treatment cycles compared to seven cycles for the initial spike experiment. A possible explanation could be that the Nyex ${ }^{\mathrm{TM}}$ adsorbent once regenerated a number of times is more active, enhancing the adsorption as well as the regeneration process. Brown et al. [20] showed that the adsorptive capacity of Nyex ${ }^{\mathrm{TM}}$ is enhanced on regeneration, possibly due to the breakup of the edges of the graphene layers in the adsorbent molecules, thereby increasing surface roughness. This enhances the contribution from the edges and which would account for the greater adsorption observed for successive spiking experiments. In addition, during the analyses of all cycles, no toxic metaldehyde breakdown 
by-products, in particular the hazardous metaldehyde monomer unit, acetaldehyde [27], were observed suggesting that complete oxidation of the metaldehyde took place.

The experiments on the adsorption and electrochemical regeneration process showed that metaldehyde removal is efficient and that no waste adsorbent is generated, with the adsorbent material able to be continuously regenerated and used for subsequent adsorption, although the energy consumption is relatively high. This represents a major advantage over processes that are based solely on adsorption where spent adsorbent material has to be disposed of, usually in landfills. Such disposal could potentially lead to leaching of metaldehyde back to the environment or simply to substantially greater treatment costs. For other adsorbent materials used to remove metaldehyde from drinking water, degradation may also result in the formation of complex chemicals such as phenolic carbon [7], and functionalised resins [28].

To our knowledge, though there are adsorption processes that have been reported to remove metaldehyde to residual concentrations in drinking water below the EU and UK regulatory limits, no process has previously reported the destruction of metaldehyde to concentrations meeting EU and UK regulatory limits. This is the first time that metaldehyde removal and destruction has been shown using this adsorption and electrochemical regeneration process under lab conditions. Spiking experiments has shown the process is repeatable and has the potential for operation without changing the adsorbent material. However, large-scale continuous treatment at higher flow rates and greater energy efficiency is needed to completely demonstrate that this adsorption and electrochemical regeneration process is viable on an industrial scale.

\subsection{Evaluation of Environmental Parameters on the Adsorption and Electrochemical Regeneration Technology}

Drinking water sources often have different $\mathrm{pH}$ depending on the nature of the water source; water from peat sources are acidic in nature [29], whereas hard water rich in clay and limestone have an alkaline $\mathrm{pH}$. To test the effect of $\mathrm{pH}$ on the removal rate of metaldehyde (average starting concentration of $8000 \mu \mathrm{g} / \mathrm{L}$ ) by the adsorption and electrochemical regeneration process, experiments were conducted at $\mathrm{pH} 3$ and 10 and compared to those at $\mathrm{pH}$ 6-7. In all cases, linear metaldehyde removal was observed but the combined adsorption and electrochemical regeneration process was much more effective at low and neutral $\mathrm{pH}$ than under alkaline conditions (Figure 5A).

A possible explanation could be that, under alkaline conditions, the adsorption stage is hindered due to the interaction of $\mathrm{OH}^{-}$ions with the adsorbent material, which has an overall positive charge, thereby reducing the density of sites available for metaldehyde sorption. Under acidic or neutral conditions no such interaction occurs and maximum adsorption of metaldehyde is possible.

All previous experiments have been conducted using synthetic deionised water. To test the adsorption and electrochemical regeneration process under "natural" conditions peat water containing $10 \mathrm{mg} / \mathrm{L}$ Total Organic Carbon (TOC) was used to prepare a metaldehyde test solution (see Section 2.1) and compared to the standard test solutions prepared in deionised water. A similar trend for metaldehyde removal was obtained in either case; however, the removal efficiency was reduced in the presence of high NOM peat water (decrease of about $20 \%$, Figure 5B). A possible explanation could be that for the peat water/metaldehyde solution, competition for active binding sites on Nyex ${ }^{\mathrm{TM}}$ 
occurs due to the presence of other organic components in peat water. However, it clearly showed that even in the presence of other organics, the adsorption and electrochemical regeneration process can remove/destroy more metaldehyde compared to advanced oxidation processes, which are dependent on the TOC levels [15].

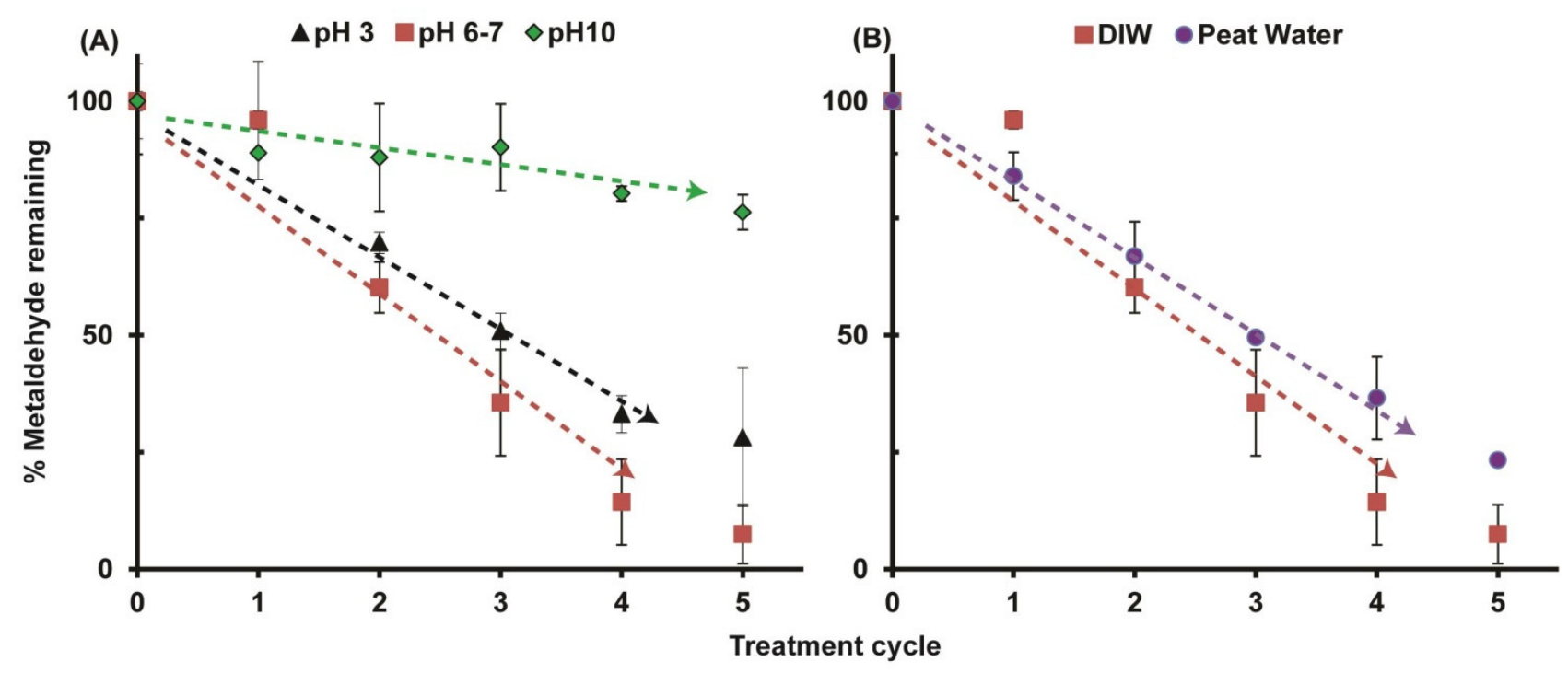

Figure 5. Metaldehyde remaining (expressed as a percentage of the mean starting concentration of $8000 \mu \mathrm{g} / \mathrm{L}$ ) after successive treatment cycles using the coupled adsorption and electrochemical regeneration technology (A) for different initial pHs and (B) in the presence and in the absence of other organics in peat water. Dotted arrows indicate generalised trends. Bars indicate the error; when they are not visible, the error bar is smaller than the symbol used. All experiments were carried out with mixing and regeneration times of $15 \mathrm{~min}$ and a current of $0.5 \mathrm{~A}$.

\section{Conclusions}

Coupled adsorption and electrochemical organic destruction technology using $\mathrm{Nyex}^{\mathrm{TM}}$ can effectively both remove and destroy metaldehyde in drinking water. Under test conditions of $15 \mathrm{~min}$ mixing, $15 \mathrm{~min}$ regeneration, $0.5 \mathrm{~A}$ current and near neutral $\mathrm{pH}$, metaldehyde was reduced from $11 \mu \mathrm{g} / \mathrm{L}$ to residual concentrations of less than the EU/UK regulatory limit of $0.1 \mu \mathrm{g} / \mathrm{L}$ without the formation of any known metaldehyde toxic breakdown by-products. Spiking experiments have showed that the process is repeatable without adsorbent waste being generated. Furthermore, the effectiveness of the process seems unaffected by high NOM peat water, indicating the potential of this technology for the treatment of drinking water, much of which in the UK is derived from upland peaty catchments. Detailed characterization of the $\mathrm{Nyex}^{\mathrm{TM}}$ and the development of a detailed mechanistic model of the adsorption processes, including those impacting solution $\mathrm{pH}$, was beyond the scope of the present paper, but is the subject of future studies. Further work is also being carried out to investigate the continuous application of this technology on a larger scale. 


\section{Acknowledgments}

This and on-going work are funded by a Knowledge Transfer Partnership grant (KTP08959) funded by the UK Technology Strategy Board (now Innovate UK) to the University of Manchester and Arvia $^{\mathrm{TM}}$ Technology Ltd. The authors would like to thank Alastair Bewsher, Holly Barden, Nuria De Las Heras and Paul Lythgoe for their analytical support; Stuart Rae for providing peat water samples; and Roy Wogelius for discussions.

\section{Author Contributions}

Mohammed A. Nabeerasool executed the study and wrote the manuscript under the supervision of Andrew K. Campen, Nigel W. Brown, David A. Polya and Bart E. van Dongen, who all contributed equally towards the design and interpretation of the study and the review of the manuscript.

\section{Conflicts of Interest}

All experiments and chemical analyses were conducted independently at the University of Manchester without any involvement of employees of Arvia Technology Ltd and as such the authors declare no conflict of interest.

\section{References}

1. WHO/UNICEF. Progress on Drinking Water and Sanitation-2014 Update. 2014. Available online: http://www.wssinfo.org/fileadmin/user_upload/resources/JMP_report_2014_webEng.pdf (accessed on 10 August 2014).

2. National Academy of Sciences. Safe Drinking Water Is Essential. 2008. Available online: http://www.drinking-water.org/html/en/Treatment/index.html (accessed on 11 August 2014).

3. United State Environmental Protection Agency. Reregistration Eligibility Decision for Metaldehyde. Prevention, Pesticides and Toxic Substances. 2006. Available online: http:/www.epa.gov/ oppsrrd1/REDs/metaldehyde_red.pdf (accessed on 20 October 2014).

4. Autin, O.; Hart, J.; Jarvis, P.; MacAdam, J.; Parsons, S.A.; Jefferson, B. The impact of background organic matter and alkalinity on the degradation of the pesticide metaldehyde by two advanced oxidation processes: $\mathrm{UV} / \mathrm{H}_{2} \mathrm{O}_{2}$ and $\mathrm{UV} / \mathrm{TiO}_{2}$. Water Res. 2013, 47, 2041-2049.

5. Pesticide News. An international perspective on the health and environmental effects of pesticides. J. Pestic. Action Netw. UK 2001, 53, 1-21.

6. The Food and Environment Research Agency (FERA). Pesticide Usage Statistics. 2013. Available online: http://pusstats.csl.gov.uk/myindex.cfm (accessed on 11 August 2014).

7. Busquets, R.; Kozynchenko, O.P.; Whitby, R.L.D.; Tennison, S.R.; Cundy, A.B. Phenolic carbon tailored for the removal of polar organic contaminants from water: A solution to the metaldehyde problem? Water Res. 2014, 61, 46-56.

8. Shu, Z.; Bolton, J.R.; Belosevic, M.; el Din, M.G. Photodegradation of emerging micropollutants using the medium-pressure $\mathrm{UV} / \mathrm{H}_{2} \mathrm{O}_{2}$ Advanced Oxidation Process. Water Res. 2013, 47, 2881-2889. 
9. Drinking Water Inspectorate (DWI). DWI PR14 Guidance-Pesticides including Metaldehyde. 2013. Available online: http://dwi.defra.gov.uk/stakeholders/price-review-process/PR14-guidancepesticide.pdf (accessed on 1 July 2014).

10. Drinking Water Inspectorate (DWI). What are the drinking water standards? 2010. Available online: http://dwi.defra.gov.uk/consumers/advice-leaflets/standards.pdf (accessed on 1 July 2014).

11. Environment Food and Rural Affairs Committee. House of Commons. UK Natural Environment White Paper: Written Evidence. 2011. Available online: http://www.publications.parliament.uk/pa/ cm201012/cmselect/cmenvfru/writev/whitepaper/wp_consolidated.pdf (accessed on 27 August 2014).

12. Briefing Paper on Metaldehyde on Drinking Water Sources. Available online: http://www. getpelletwise.co.uk/uploads/literature/pdf/FINAL_WaterUK_Metaldehyde_Briefing_31_Oct_2012.pdf (accessed on 17 June 2015).

13. Hall, T.; Holden, B.; Haley, J. Treatment for metaldehyde and other problem pesticides. In Proceedings of the 4th Developments in Water Treatment and Supply Conference, Cheltenham, UK, 7-8 June 2011.

14. Doria, F.C.; Borges, A.C.; Kim, J.K.; Nathan, A.; Joo, J.C.; Campos, L.C. Removal of Metaldehyde Through Photocatalytic Reactions Using Nano-Sized Zinc Oxide Composites. Water Air Soil Pollut. 2013, 224, 1434-1443.

15. James, C.P.; Germain, E.; Judd, S. Micropollutant removal by advanced oxidation of microfiltered secondary effluent for water reuse. Sep. Purif. Technol. 2014, 127, 77-83.

16. Autin, O.; Hart, J.; Jarvis, P.; MacAdam, J.; Parsons, S.A.; Jefferson, B. Comparison of UV/TiO 2 and $\mathrm{UV} / \mathrm{H}_{2} \mathrm{O}_{2}$ processes in an annular photoreactor for removal of micropollutants: Influence of water parameters on metaldehyde removal, quantum yields and energy consumption. Appl. Catal. B Environ. 2013, 138-139, 268-275.

17. Veolia Water Solutions \& Technologies and Affinity Water. Removal of Metaldehyde from Drinking Water. 2013. Available online: http://veoliawatertechnologies.com/news-media/articles/ metaldehyde-removal.htm (accessed on 20 October 2014).

18. Asghar, H.M.A.; Roberts, E.P.L.; Hussain, S.N.; Campen, A.K.; Brown, N.W. Wastewater treatment by adsorption with electrochemical regeneration using graphite-based adsorbents. J. Appl. Electrochem. 2012, 42, 797-807.

19. Mohammed, F.; Roberts, E.P.L.; Campen, A.K.; Brown, N.W. Wastewater treatment by multi-stage batch adsorption and electrochemical regeneration. J. Electrochem. Sci. Eng. 2012, 2, 223-236.

20. Brown, N.W.; Roberts, E.P.L.; Garforth, A.A.; Dryfe, R.A.W. Electrochemical regeneration of a carbon-based adsorbent loaded with crystal violet dye. Electrochim. Acta 2004, 49, 3269-3281.

21. Brown, N.W.; Roberts, E.P.L.; Chasiotis, A.; Cherdron, T.; Sanghrajka, N. Atrazine removal using adsorption and electrochemical regeneration. Water Res. 2004, 38, 3067-3074.

22. Brown, N.W.; Roberts, E.P.L.; Garforth, A.A.; Dryfe, R.A.W. Treatment of dyehouse effluents with a carbon-based adsorbent using anodic oxidation regeneration. Water Sci. Technol. 2004, 49, 219-225.

23. Hussain, S.N.; Roberts, E.P.L.; Asghar, H.M.A, Campen, A.K.; Brown, N.W. Oxidation of phenol and the adsorption of breakdown products using a graphite adsorbent with electrochemical regeneration. Electrochim. Acta 2013, 92, 20-30. 
24. Environment Agency. The Determination of Metaldehyde in Waters Using Chromatography with Mass Spectrometric Detection Methods for the Examination of Waters and Associated Materials. 2009. Available online: https://www.gov.uk/government/uploads/system/uploads/attachment_data/ file/316782/Metaldehyde-226b.pdf (accesses on 10 August 2014).

25. Extraction of Metaldehyde, Geosmin and 2-Methylisoborneol from Water; Sample Preparation Products Application Note: ENV611; Kinesis: Bothell, WA, USA, 2012; pp. 1-3.

26. Mehta, M.P.; Flora, J.R.V. Effects of electrochemical treatment of granular activated carbon on surface acid groups and the adsorptive capacity for phenol. Water Res. 1997, 31, 2171-2176.

27. Material Safety Data Sheet. Available online: http://www.herbiguide.com.au/MSDS/MMETAL 15_60408-0910.PDF (accessed on 11 August 2014).

28. Tao, B.; Fletcher, A.J. Catalytic degradation and adsorption of metaldehyde from drinking water by functionalized mesoporous silicas and ion-exchange resin. Sep. Purif. Technol. 2014, 124, 195-200.

29. Holden, B. Peatland hydrology and carbon release: Why small-scale process matters. Philos. Trans. R. Soc. 2005, 363, 2891-2913.

(C) 2015 by the authors; licensee MDPI, Basel, Switzerland. This article is an open access article distributed under the terms and conditions of the Creative Commons Attribution license (http://creativecommons.org/licenses/by/4.0/). 